\title{
Anemia among pregnant women in Southeast Ethiopia: prevalence, severity and associated risk factors
}

Filagot Kefiyalew ${ }^{1+}$, Endalew Zemene ${ }^{2}$, Yaregal Asres $^{2}$ and Lealem Gedefaw ${ }^{2 *+}$

\begin{abstract}
Background: Anemia is a significant public health problem in developing countries, particularly in pregnant women. It may complicate pregnancy, sometimes resulting in tragic outcomes. There is a lack of information on the magnitude of anemia among pregnant women in Southeast Ethiopia. The aim of this study is, therefore, to determine the prevalence of anemia and assess associated factors among pregnant women attending antenatal care (ANC) at Bisidimo Hospital in Southeast Ethiopia.
\end{abstract}

Methods: A facility-based cross-sectional study, involving 258 pregnant women, was conducted from March to June 2013. Socio-demographic, medical and obstetric data of the study participants were collected using structured questionnaire. Hemoglobin was measured using a hematology analyzer and faecal specimens were examined to detect intestinal parasites. Anemia in pregnancy was defined as hemoglobin $<11 \mathrm{~g} / \mathrm{dl}$.

Results: Overall, prevalence of anemia was $27.9 \%$, of which $55 \%$ had mild anemia. Rural residence (AOR $=3.3,95 \%$ Cl: $1.5-7.4)$, intestinal parasitic infection (IPI) $(\mathrm{AOR}=2.5,95 \% \mathrm{Cl}: 1.3-4.8)$ and history of heavy cycle (AOR $=2.7,95 \%$ Cl: 1.3-1.7) were predictors of anemia.

Conclusions: This study showed moderate prevalence of anemia among the pregnant women, with a sizable proportion having severe anemia. Routine testing of pregnant women for IPIs and creating awareness on factors predisposing to anemia is recommended.

Keywords: Anemia, Associated factors, Pregnant women, Southeast Ethiopia

\section{Background}

Anemia is defined as a condition in which there is less than the normal hemoglobin $(\mathrm{Hb})$ level in the body, which decreases oxygen-carrying capacity of red blood cells to tissues. Anemia is a global public health problem affecting both developed and developing countries with major consequences for human health as well as social and economic development. It occurs at all stages of the life cycle $[1,2]$.

Anemia in pregnancy remains one of the most intractable public health problems in developing countries. Globally, anemia contributes to $20 \%$ of all maternal deaths. Although not always shown to have a causal link, severe

\footnotetext{
* Correspondence: lealem.gedefaw@ju.edu.et

${ }^{\dagger}$ Equal contributors

2Department of Medical Laboratory Science and Pathology, College of Public Health and Medical Sciences, Jimma University, Jimma, Ethiopia
}

Full list of author information is available at the end of the article anemia contributes to maternal morbidity and mortality [3-8]. Anemia in pregnancy may also lead to premature births [9], low birth weight [10], fetal impairment and infant deaths [11].

Apart from maternity-related complications, anemia has major consequences on human health and social and economic development. It adversely affects physical and cognitive development in children [12] and is associated with increased frailty risk in community-dwelling older adults [13]. Recently, increased risk of psychiatric disorders among children and adolescents with iron deficiency anemia has also been documented [14].

Knowledge of the relative importance of the different etiological factors forms the basis for intervention strategies to control anemia. In Sub-Saharan Africa, the causes of anemia during pregnancy are multifactorial. These include an iron and folate deficient diet and 
infections such as malaria, hookworms, and increasingly human immunodeficiency virus. Most of these conditions can be prevented by creating awareness and providing affordable interventions [15-18].

Anemia is a significant public health problem in Ethiopia. According to the 2012 Ethiopian Central Statistical Agency report, nationally, $44 \%$ of children aged 6-59 months were anemic, with $21 \%, 20 \%$ and $3 \%$ having mild, moderate and severe anemia. Moreover, $17 \%$ of women aged 15-49 were anemic; of which $13 \%$ had mild anemia, $3 \%$ were moderately anemic, and less than $1 \%$ were severely anemic. Iron deficiency anemia was ranked as one of the significant micronutrient deficiency problems in Ethiopia [19,20].

Epidemiological studies done on prevalence of anemia in pregnant women in Ethiopia have reported varying magnitude of anemia and identified several factors associated with anemia [21-23]. Determination of the magnitude of anemia among pregnant women helps to monitor health of the pregnant women, contributing to reduction in maternal morbidity and mortality. Also, assessment of factors predisposing to anemia in a local area enables to take targeted intervention activities. Therefore, this study is aimed at determining prevalence of anemia and assessing associated risk factors among pregnant women attending antenatal care (ANC) at Bisidimo Hospital in Southeast Ethiopia.

\section{Methods}

\section{Study setting}

The study was conducted among pregnant women attending ANC in Bisidimo Hospital. Bisidimo Hospital is a district hospital found in East Harerege zone in Southeast Ethiopia. The hospital is located in Babile Woreda (equivalent to district), $535 \mathrm{Km}$ Southeast of the capital Addis Ababa. The geographical coordinates of the district are approximately $9^{\circ} 8^{\prime} 41 \mathrm{~N}$ latitude and $42^{\circ} 12^{\prime}$ $48 \mathrm{E}$ longitude with an altitude of 1357 meters above sea level. The hospital serves more than 250,000 inhabitants of the district and neighboring districts. The study was carried out from March to June, 2013.

\section{Study design and sampling method}

A cross sectional study was conducted among pregnant women attending ANC of the hospital. A total of 258 pregnant women were enrolled in this study. Sample size was estimated using the general formula for single population proportion, with the following assumptions: anemia prevalence (P) of $21.3 \%$ [23] and using the $95 \%$ confidence level and 5\% marginal error. This gave us 258; hence, all pregnant women visiting ANC during March to June 2013, were included consecutively. Pregnant women of all trimesters, who were willing to take part in the study, were included. On the other hand, pregnant women receiving therapy for anemia, severely ill thus unable to respond to the questionnaire and not willing to take part in the study were excluded.

\section{Data collection}

Data on socio demographic, obstetric and medical history of pregnant women were collected using structured questionnaire. The questionnaire, first prepared in English and translated into the local language Afan Oromo, was administered by two trained nurses. Weight and height of the pregnant women were also measured for computing body mass index (BMI). Moreover, approximately $4 \mathrm{ml}$ of venous blood was collected using vacutainer tubes. Hematological analyses were done using CELL DYN 1800 (Abott Laboratories Diagnostics Division, USA). Hematological parameters measured include: $\mathrm{Hb}$, mean cell volume (MCV), mean cell hemoglobin $(\mathrm{MCH})$ and mean cell hemoglobin concentration (MCHC).

In this study, anemia in pregnancy was defined as $\mathrm{Hb}<11 \mathrm{~g} / \mathrm{dl}$. Also mild, moderate and severe anemia was defined as $\mathrm{Hb}$ measurements between $10-10.9 \mathrm{~g} / \mathrm{dl}$, 7-9.9 $\mathrm{g} / \mathrm{dl}$ and less than $7 \mathrm{~g} / \mathrm{dl}$, respectively [24]. Apart from the hematological analyses, thick and thin blood films were prepared, stained using $10 \%$ Giemsa stain for 10 minutes and examined microscopically to investigate hemoparasites particularly malaria.

Also, fresh faecal specimens were collected from each study participants using a clean, leak-proof stool cups and examined for intestinal parasitic infections (IPIs) using saline wet smear and formol-ether concentration techniques, following standard procedures [25]. Two experienced microscopists examined the blood films and faecal specimens.

To assure the quality of the data, training was given to the data collectors to minimize technical and observer bias. Standard operating procedures were followed during specimen collection and laboratory procedures. Control reagents were run to check the accuracy and precision of the data generated by the hematology analyzer.

\section{Data analysis}

Data were entered in to EPI data version 3.1 and cleaned. Finally, data were analyzed using SPSS version 20 for windows (SPSS, Chicago, IL, USA). Data were summarized in tables and figure. Bivariate and multivariate logistic regression analyses were done to identify independent predictors of anemia. Variables with pvalue $\leq 0.25$ by the bivariate analysis and other biologically plausible variables were candidates for the multiple logistic regression model. P-value was set at $<0.05$ for statistical significance.

\section{Ethical clearance}

Ethical clearance was obtained from Jimma University Ethical Review Committee. Permission was obtained from 
Bisidimo Hospital Administration before data collection. Written informed consent was obtained from each pregnant woman prior to enrollment in the study. Individuallevel obstetric and medical information obtained from the study participants was kept strictly confidential and they were assured that only aggregate data will be reported. Anemic pregnant women and pregnant women with IPIs and malaria were immediately communicated to the attending health professionals at the ANC clinic of the hospital, for treatment and follow up.

\section{Results}

Socio demographic characteristics of pregnant women A total of 258 pregnant women, age ranging 18 to 37 year (mean 26.9 \pm 4.8 ), were included in this study. Nearly half $(49.2 \%)$ of the pregnant women were within the age range of 18-26 years. Many of them were married, $223(86.4 \%)$. Majority of the pregnant women were housewives $(62.4 \%)$, rural residents $(60.5 \%)$ and illiterate (61.2\%), who were not able to read and write at least with one language. Socio-demographic profile of the study participants is demonstrated in Table 1.

\section{Obstetric and medical history of pregnant women}

Over half of the pregnant women, 134 (51.9\%) were in their second trimester of pregnancy. Thirty seven (14.3\%) of the pregnant women responded to have previous miscarriage. Majority of the pregnant women (80.2\%) were multigravidae. More than a third of the pregnant women (37.2\%) were infected with intestinal parasites (Table 2). A total of six species of intestinal parasite were identified. Ascaris lumbricoides was the predominant (19\%) intestinal parasite identified followed by the hookworms (6.2\%). Prevalence of each intestinal parasite is displayed in Figure 1. Moreover, Plasmodium species were detected in $9(3.5 \%)$ of the total blood films examined, 7 of the cases were due to Plasmodium vivax and the remaining two cases were due to Plasmodium falciparum.

\section{Prevalence of anemia among pregnant women}

The overall prevalence of anemia in this study was $27.9 \%$. The mean $\mathrm{Hb}$ value was $11.4 \pm 2.3 \mathrm{~g} / \mathrm{dl}$. Of the anemic pregnant women, $55 \%, 32.5 \%$ and $12.5 \%$ had mild, moderate and severe anemia, respectively.

Table 1 Socio-demographic characteristics and anemia among the pregnant women, Bisidimo Hospital, 2013

\begin{tabular}{|c|c|c|c|c|c|}
\hline \multirow[t]{3}{*}{ Variables } & \multicolumn{3}{|c|}{ Anemia diagnosis } & \multirow[t]{3}{*}{ COR $(95 \% \mathrm{Cl})$} & \multirow[t]{3}{*}{ P-value } \\
\hline & Anemic & Not anemic & Total & & \\
\hline & No (\%) & No (\%) & No (\%) & & \\
\hline \multicolumn{6}{|l|}{ Age in years } \\
\hline $18-26$ & $35(27.6)$ & $92(72.4)$ & $127(49.2)$ & 1 & \\
\hline $26-34$ & 35 (30.7) & 79 (69.3) & $114(44.2)$ & $1.2(0.7-2.0)$ & 0.592 \\
\hline$\geq 34$ & $2(11.8)$ & $15(88.2)$ & $17(6.6)$ & $0.4(0.1-1.6)$ & 0.178 \\
\hline \multicolumn{6}{|l|}{ Occupation } \\
\hline Housewives & $41(25.5)$ & $120(74.5)$ & $161(62.4)$ & $1.4(0.3-6.7)$ & 0.700 \\
\hline Employed & 19 (32.8) & $39(67.2)$ & $58(22.5)$ & $1.9(0.4-10.0)$ & 0.426 \\
\hline Farmers & $10(34.5)$ & $19(65.5)$ & $29(11.2)$ & $2.1(0.4-11.9)$ & 0.399 \\
\hline Others* & $2(20.0)$ & $8(80.0)$ & $10(3.9)$ & 1 & \\
\hline \multicolumn{6}{|l|}{ Residence } \\
\hline Urban & $17(16.7)$ & $85(73.3)$ & $102(39.5)$ & & \\
\hline Rural & $55(35.3)$ & $101(64.7)$ & $156(60.5)$ & $2.7(1.5-5.0)^{*}$ & 0.001 \\
\hline \multicolumn{6}{|c|}{ Educational status } \\
\hline Illiterate & $40(25.3)$ & $118(74.3)$ & $158(61.2)$ & $0.7(0.4-1.3)$ & 0.244 \\
\hline Literate & $32(32)$ & $68(68)$ & $100(38.8)$ & 1 & \\
\hline \multicolumn{6}{|l|}{ Marital status } \\
\hline Married & $56(25.1)$ & $167(74.9)$ & $223(86.4)$ & 1 & \\
\hline Unmarried & $16(45.7)$ & $19(54.3)$ & 35 (13.6) & $2.5(1.2-5.2)^{*}$ & 0.014 \\
\hline \multicolumn{6}{|c|}{ Body mass index } \\
\hline Low & $11(36.7)$ & $19(63.3)$ & $30(11.6)$ & $1.9(0.8-4.4)$ & 0.135 \\
\hline Normal & 30 (31.6) & $65(68.4)$ & 95 (36.8) & $1.5(.8-2.7)$ & 0.166 \\
\hline High & $31(23.3)$ & $102(76.7)$ & $133(51.6)$ & 1 & \\
\hline
\end{tabular}

*Statistically significant at $\mathrm{P}<0.05$; Cl: Confidence interval; COR: crude odds ratio, others*: Daily laborers and Merchants. 
Table 2 Clinical variables in association with anemia among the pregnant women, Bisidimo Hospital, 2013

\begin{tabular}{|c|c|c|c|c|c|}
\hline \multirow[t]{3}{*}{ Variables } & \multicolumn{3}{|c|}{ Anemia diagnosis } & \multirow[t]{3}{*}{ COR $(95 \% \mathrm{Cl})$} & \multirow[t]{3}{*}{$p$-value } \\
\hline & Anemic & Not anemic & Total & & \\
\hline & No (\%) & No (\%) & No (\%) & & \\
\hline \multicolumn{6}{|c|}{ History of miscarriage } \\
\hline Yes & $9(24.3)$ & $28(75.7)$ & $37(14.3)$ & $0.8(0.4-1.8)$ & 0.600 \\
\hline No & $63(28.5)$ & $158(71.5)$ & $221(85.7)$ & 1 & \\
\hline \multicolumn{6}{|c|}{ History of heavy cycle } \\
\hline$\leq 5$ days & $45(25.0)$ & $135(75.0)$ & $180(69.8)$ & 1 & \\
\hline$>5$ days & 27 (34.6) & $51(65.4)$ & $78(30.2)$ & $1.6(0.9-2.8)$ & 0.115 \\
\hline \multicolumn{6}{|l|}{ Trimester } \\
\hline First & $14(30.4)$ & $32(69.6)$ & $46(17.8)$ & 1 & \\
\hline Second & 29(21.6) & $105(78.4)$ & $134(51.9)$ & $0.6(0.3-1.3)$ & 0.230 \\
\hline Third & $29(37.2)$ & $49(62.8)$ & $78(30.2)$ & $1.4(0.6-2.9)$ & 0.447 \\
\hline \multicolumn{6}{|l|}{ Parity } \\
\hline 0 & 10 (19.6) & $41(80.4)$ & $51(19.8)$ & 1 & \\
\hline $1-4$ & $55(30.4)$ & $126(69.6)$ & $181(70.2)$ & $1.8(0.8-3.8)$ & 0.134 \\
\hline$>5$ & $7(26.9)$ & $19(73.1)$ & $26(10.1)$ & $1.5(0.5-4.6)$ & 0.466 \\
\hline \multicolumn{6}{|c|}{ Birth interval $(n=211)$} \\
\hline$\leq 2$ years & $56(30.1)$ & $(69.9)$ & $186(88.2)$ & $1.4(0.5-3.6)$ & 0.530 \\
\hline$>2$ years & $6(24.0)$ & $19(76.0)$ & $25(11.8)$ & 1 & \\
\hline \multicolumn{6}{|c|}{ Red meat/poultry/fish consumption } \\
\hline Yes & $22(31.4)$ & $48(68.6)$ & $70(27.1)$ & 1 & \\
\hline No & $50(26.6)$ & $138(73.4)$ & $188(72.9)$ & $1.3(0.7-2.3)$ & 0.442 \\
\hline \multicolumn{6}{|c|}{ Fruit/vegetable consumption } \\
\hline Yes & $22(26.2)$ & $62(73.8)$ & $84(32.6)$ & 1 & \\
\hline No & $50(28.7)$ & $124(71.3)$ & $174(67.4)$ & $0.9(0.5-1.6)$ & 0.880 \\
\hline \multicolumn{6}{|c|}{ Intestinal parasite detected } \\
\hline Yes & $40(41.7)$ & $56(58.3)$ & $96(37.2)$ & $1.9(1.1-3.4)^{*}$ & 0.019 \\
\hline No & $40(24.7)$ & $122(75.3)$ & $162(62.8)$ & 1 & \\
\hline \multicolumn{6}{|c|}{ Malaria infection } \\
\hline Yes & $3(33.3)$ & $6(66.7)$ & $9(3.5)$ & $0.3(0.4-2.6)$ & 0.278 \\
\hline No & 77 (30.9) & $172(69.1)$ & $249(96.5)$ & 1 & \\
\hline
\end{tabular}

*Statistically significant at $\mathrm{P}<0.05$.

The prevalence of anemia was higher $(34.6 \%)$ in pregnant women in the age group of 18-26 years; however, the difference was not significant. Majority of the study participants were rural residents with significantly $(\mathrm{P}=0.001)$ higher prevalence of anemia compared to their urban counterparts. Anemia in those infected with intestinal parasites was significantly higher $(\mathrm{P}=0.019)$ than the noninfected ones. Similarly, prevalence of anemia was significantly higher ( $\mathrm{AOR}=2.7,95 \% \mathrm{CI}$ : 1.3-1.7) in pregnant women who reported history of heavy cycle (Table 2).

\section{Associated factors of anemia}

After adjusting for other variables: residence in rural area $(\mathrm{AOR}=3.3,95 \% \mathrm{CI}: 1.5-7.4)$, intestinal parasitic infection (IPI) $(\mathrm{AOR}=2.5,95 \% \mathrm{CI}: 1.3-4.8)$ and history of heavy menstrual cycle ( $>5$ days of menses) $(\mathrm{AOR}=$ 2.7, 95\% CI: 1.3-1.7) were the predictors of anemia among the pregnant women (Table 3 ).

\section{Discussion}

The overall prevalence of anemia among pregnant women was $27.9 \%$. According to WHO classification of the public health importance of anemia [24], it is a moderate public health problem among the pregnant women in our study. Out of the anemic pregnant women, however, $12.5 \%$ had severe anemia, $\mathrm{Hb}$ concentration of below $7 \mathrm{mg} / \mathrm{dl}$. 


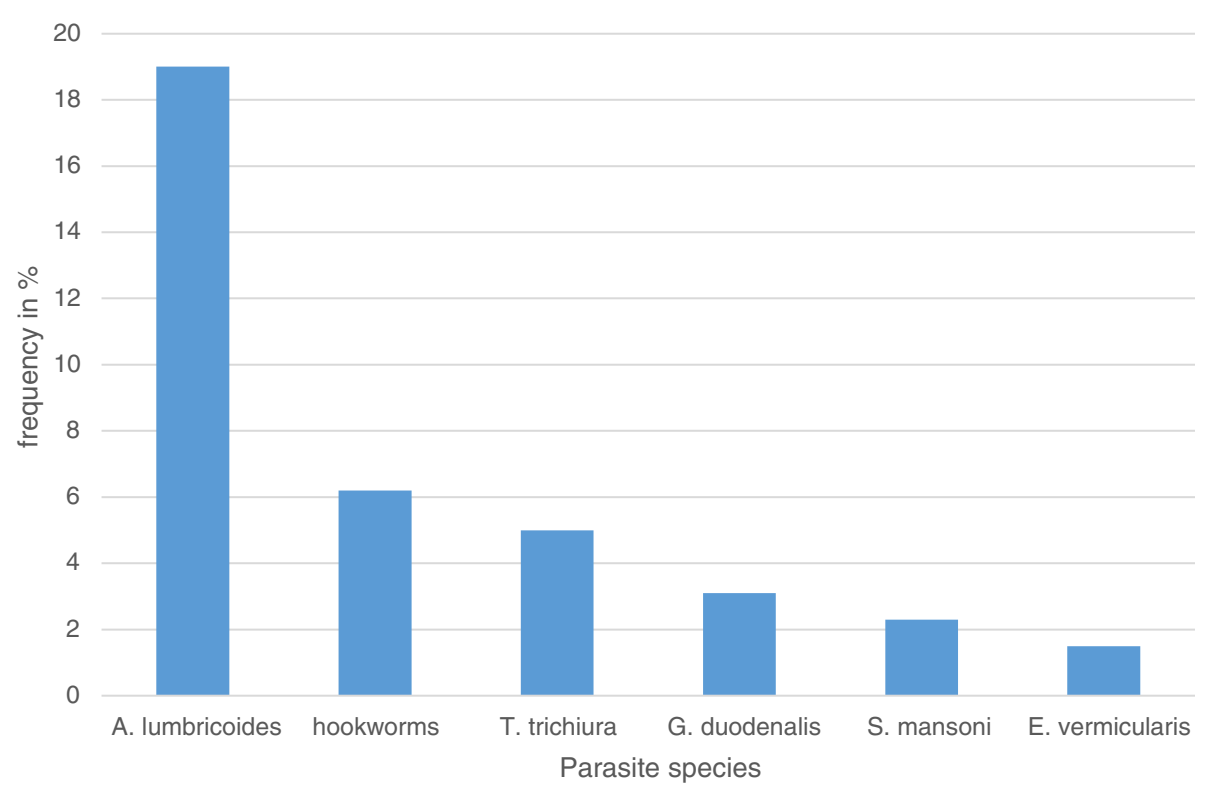

Figure 1 Prevalence of intestinal parasites identified among the pregnant women, Bisidimo hospital, Southeast Ethiopia, 2013.

The overall prevalence of anemia obtained in this study is higher than reports from Gondar (21.6\%) [26], Nigeria (23.2\%) [18] and Turkey (27.1\%) [27]. This might be due difference in the socio-demographic factors and lack of awareness about the consequences of anemia in our study participants. In this study, pregnant women on iron supplementation were not included, while these were included in studies done in Gondar and Turkey. In the study done in Nigeria [18], it has been indicated that use of hematinics and antimalarial drugs is a common practice in Nigeria. This may possibly lower the prevalence of anemia among the pregnant women in Nigeria compared to the pregnant women in our study.

Higher magnitudes of anemia were reported from Arsi (36.6\%) [28], Addis Ababa (33\%) [23], and around Gilgel Gibe dam area in southwest Ethiopia (53.9 \%) [29], Eastern Sudan (62.6\%) [30]. This might be due to variation in sample size and presence of high malaria infection. For instance the prevalence of malaria in the study done around Gilgel Gibe area (11.6\%) and eastern Sudan (reported $13.7 \%$ of $P$. falciparum malaria) were relatively high which might have contributed to the high prevalence of anemia.

In this study, mild anemia was common followed by moderate anemia. Similar findings were reported in other local studies [23,29] and the study done in Nigeria [18].

Heavy infection with soil-transmitted helminthes (STHs), particularly the hookworms, predisposes pregnant women and individuals with low iron store to anemia. In this study, more than a third of the pregnant women were infected with intestinal parasites, Ascaris lumbricoides and the Hook worms being predominant. Pregnant women with IPIs were 2.5 times more likely to be anemic compared to their non-infected counterparts. Other local studies [26,29] also documented similar findings.

A significantly higher prevalence of anemia was found among pregnant women who were from rural areas. Pregnant women from rural areas were more than three times more likely to be anemic than their urban counterparts. Association of rural residence with anemia has also been reported earlier [26]. The higher prevalence of anemia among pregnant women from rural areas is likely related to lack of information about adequate nutrition during pregnancy, economic factors and inaccessibility of health care centers.

Pregnant women with a history of heavy cycle were more anemic than those with normal menstruation cycle. In this study pregnant women with a history of heavy cycle were 2.7 times more likely to be anemic than those who had normal menstruation cycle $(\mathrm{AOR}=2.7$, 95\% CI: 1.3-1.7).

In this study, the association of other obstetric and dietary habits with anemia was also assessed (Table 2). Accordingly, no significant association of history of miscarriage, parity, trimester, birth interval, body mass index, dietary habit, educational status and occupation with anemia was obtained. In contrast, association of anemia with multiparity and intake of vegetables and fruits was reported in the study done in Arsi [28]. This is in contrary with studies done by Alem et al. [26], and Karaoglu et al. [27]. This might be due to variation in method and study subject involved.

Malaria infection during pregnancy is life-threatening. In this study, nine of the pregnant women were malaria positive by thick film microscopy. It is likely that this 
Table 3 Predictors of anemia among the pregnant women, Bisidimo Hospital, 2013

\begin{tabular}{|c|c|c|c|c|}
\hline Variable & COR $(95 \% \mathrm{Cl})$ & P-value & AOR $(95 \% \mathrm{Cl})$ & P-value \\
\hline \multicolumn{5}{|l|}{ Age in years } \\
\hline $18-26$ & 1 & 1 & & \\
\hline $26-34$ & $1.2(0.7-2.0)$ & 0.592 & $1.7(0.9-3.2)$ & 0.127 \\
\hline$\geq 34$ & $0.4(0.1-1.6)$ & 0.178 & $0.4(0.1-1.8)$ & 0.202 \\
\hline \multicolumn{5}{|l|}{ Residence } \\
\hline Urban & 1 & 1 & & \\
\hline Rural & $2.7(1.5-5.0)$ & $0.001^{*}$ & $3.3(1.5-7.4)^{*}$ & 0.003 \\
\hline \multicolumn{5}{|l|}{ Marital status } \\
\hline Married & 1 & 1 & & \\
\hline Unmarried & $2.5(1.2-5.2)$ & 0.014 & $2.0(0.8-4.6)$ & 0.113 \\
\hline \multicolumn{5}{|c|}{ Educational status } \\
\hline Illiterate & $0.7(0.4-1.3)$ & 0.244 & $0.6(0.3-1.2)$ & 0.153 \\
\hline Literate & 1 & 1 & & \\
\hline \multicolumn{5}{|c|}{ History of heavy cycle } \\
\hline$\leq 5$ days & 1 & 1 & & \\
\hline$>5$ days & $1.6(0.9-2.8)$ & 0.115 & $2.7(1.3-1.7)^{*}$ & 0.006 \\
\hline \multicolumn{5}{|l|}{ Trimester } \\
\hline First & 1 & & & \\
\hline Second & $0.6(0.3-1.3)$ & 0.230 & $1.3(0.5-3.2)$ & 0.639 \\
\hline Third & $1.4(0.6-2.9)$ & 0.447 & $1.6(0.7-4.1)$ & 0.289 \\
\hline \multicolumn{5}{|l|}{ Parity } \\
\hline 0 & 1 & & 1 & \\
\hline $1-4$ & $1.8(0.8-3.8)$ & 0.134 & $1.3(0.5-3.2)$ & 0.639 \\
\hline$>5$ & $1.5(0.5-4.6)$ & 0.466 & $1.6(0.7-4.1)$ & 0.289 \\
\hline \multicolumn{5}{|c|}{ Intestinal parasite detected } \\
\hline Yes & $1.9(1.1-3.4)$ & 0.019 & $2.5(1.3-4.8)^{*}$ & 0.007 \\
\hline No & 1 & & 1 & \\
\hline \multicolumn{5}{|c|}{ Body mass index } \\
\hline Low & $1.9(0.8-4.4)$ & 0.135 & $2.4(0.9-6.3)$ & 0.084 \\
\hline Normal & $1.5(.8-2.7)$ & 0.166 & $1.7(0.9-3.2)$ & 0.134 \\
\hline High & 1 & & 1 & \\
\hline
\end{tabular}

magnitude of malaria is underestimated in this study, as submicroscopic Plasmodium infections are missed by the diagnostic method used [31]. Most of the detected cases (seven out of nine) were due to Plasmodium vivax. Malaria infection during pregnancy in the area calls urgent intervention activities targeting pregnant women to be in place to prevent tragic outcomes of the infection during pregnancy [32,33]. In Ethiopia, almost all cases of malaria are caused by $P$. falciparum and $P$. vivax, the former causing about $60 \%$ of malaria cases. Major transmission of malaria occurs in Ethiopia from September to December, following the major rains. Minor transmission occurs from April to May following the minor rains. In
Ethiopia, $P$. vivax is relatively common during the minor transmission periods, which is also observed in this study.

The findings of this study should be interpreted with caution due to the following limitations of the study. First, due to the cross sectional study design used, whether anemia preceded the predisposing factors or the vice versa could not be verified in this study. We exclude those severely ill pregnant women and unable to respond due to difficulty of getting venous sample. This may potentially reduce the prevalence of anemia. Third, micronutrients were not measured in this study, which limits further classification of the anemia. Last, the worm burden of the STHs had not been determined. As 
a result, severity of the helminths infections could not be estimated.

\section{Conclusion}

The prevalence of anemia among pregnant women is moderate, however, sizable proportion of the pregnant women had severe anemia. Pregnant women residing in rural areas, having IPIs and history of heavy cycle had a higher risk of anemia. Awareness creation on the consequences of anemia during pregnancy should be given to women in child bearing age in general and pregnant women in particular. Routine screening and deworming of pregnant women infected with intestinal parasites is recommended.

\section{Competing interest}

The authors declared that they have no competing interests.

\section{Authors' contributions}

FK and LG conceived the study, participated in the design and data analysis. EZ and YA involved in data acquisition, laboratory work and drafted the manuscript. LG critically reviewed the manuscript. All the authors read and approved the manuscript.

\section{Acknowledgments}

We would like to thank staff members of Bisidimo Hospital, particularly the Medical laboratory staff for their cooperation during data collection. We are grateful to the study participants. This study was financially supported by Jimma University.

\section{Author details}

'Department of Clinical Laboratory, Bisidimo Hospital, East Harerege zone, Hararege, Ethiopia. ${ }^{2}$ Department of Medical Laboratory Science and Pathology, College of Public Health and Medical Sciences, Jimma University, Jimma, Ethiopia.

Received: 26 August 2014 Accepted: 24 October 2014

Published: 3 November 2014

\section{References}

1. World Health Organization/United Nations University/UNICEF: Iron Deficiency Anemia, Assessment, Prevention and Control: A Guide for Programme Managers. Geneva: WHO; 2001.

2. WHO: Reducing Risks, Promoting Healthy Life, The World health report. Geneva, Switzerland: 2001.

3. Usanga EA, Chilaka M, Archibong El: Prevalence of iron deficiency anemia in nigerian pregnant women. J Med Lab Sci 1994, 4:113.

4. Shulman CE, Graham WJ, Jilo H, Lowe BS, New L, Obiero J: Malaria is an important cause of anemia in primigravidae: Evidence from a district hospital in coastal Kenya. Trans R Soc Trop Med Hyg 1996, 90:535-539.

5. Van den Broek NR, Letsky E: Etiology of anemia in pregnancy in south Malawi. Am J Clin Nutr 2000, 72:247S-256S.

6. Marchant TJ: The health of pregnant women in rural Tanzania with specific emphasis on anemia and the impact of socially marketed insecticide treated Bed nets. Inaugural dissertation, Basel; 2002:1-188.

7. Crawley J: Reducing the burden of anemia in infants and young children in malaria endemic countries of Africa: From evidence to action. Am J Trop Med Hyg 2004, 71:25-34

8. Haas JD, Brownlie TT: Iron deficiency and reduced work capacity: A critical review of the research to determine a causal relationship. J Nutr 2001, 131:676S-688S.

9. Levy A, Fraser D, Katz M, Mazor M, Sheiner E: Maternal anemia during pregnancy is an independent risk factor for Low birth weight and preterm delivery. Eur J Obstet Gynecol Reprod Biol 2005, 122:182-186.

10. Banhidy F, Acs N, Puho EH, Czeizel AE, Doct. Sci: Iron deficiency anemia: Pregnancy outcomes with or without iron supplementation. Nutrition 2011, 27(1):65-72
11. Kalaivani K: Prevalence $\&$ consequences of anemia in pregnancy. Indian $J$ Med Res 2009, 130:627-633.

12. Walter T: Effect of iron-deficiency anemia on cognitive skills and neuromaturation in infancy and childhood. Food Nutr Bull 2003, 24:S104-S110.

13. Juarez-Cedillo T, Basurto-Acevedo L, Vega-Garcia S, Manuel-Apolinar L, CruzTesoro E, Rodriquez-Perez JM, Garcia-Hernandez N, Perez-Hernández N, Fragoso JM: Prevalence of anemia and its impact on the state of frailty in elderly people living in the community: SADEM study. Ann Hematol 2014. doi:10.1007/s00277-014-2155-4.

14. Chen MH, Su TP, Chen YS, Hsu JW, Huang KL, Chang WH, Chen TJ, Bai YM: Association between psychiatric disorders and iron deficiency anemia among children and adolescents: A nationwide population-based study. BMC Psychiatry 2013, 13:161.

15. Garcia J, Datol-Barrett E, Dizon M: Industry experience in promoting weekly iron-folic acid supplementation in the Philippines. Nutr Rev 2005, 63:S146-S151.

16. Griffin JT, Hollingsworth DT, Okell LC, Churcher TS, White M, Hinsley W Bousema T, Drakeley CJ, Ferguson NM, Basanez MG, Ghani AC: Reducing plasmodium falciparum malaria transmission in Africa: A model-based evaluation of intervention strategies. PLoS Med 2010, 7:Article no. e1000324.

17. Guyatt LH, Robert WS: The epidemiology and burden of plasmodium falciparum-related anemia among pregnant women in Sub Saharan Africa. Am J Trop Med Hyg 2001, 64:36-44.

18. Buseri FI, Uko EK, Jeremiah ZA, Usanga EA: Prevalence and risk factors of anemia among pregnant women in Nigeria. Open Hematol J 2008, 2:14-19.

19. World Health Organization, Centers for Disease Control and Prevention, Benoist B, McLean E, Egli I, Cogswell M (Eds): Worldwide Prevalence of Anemia 1993-2005. Geneva: World Health Organization; 2008.

20. Ethiopia Central Statistical Agency and ICF International: 2011 Ethiopia Demographic and Health Survey: Key Findings. Calverton, Maryland, USA: CSA and ICF International; 2012

21. Melku M, Addis Z, Alem M, Enawgaw B: Prevalence and Predictors of Maternal Anemia During Pregnancy in Gondar, Northwest Ethiopia: An Institutional Based Cross-Sectional Study, Anemia. Hindawi Publishing Corporation; 2014. Article ID 108593, doi:10.1155/2014/108593.

22. Desalegn S: Prevalence of anemia in pregnancy in jimma town, southwestern Ethiopia. Ethiop Med J 1993, 31:251-258.

23. Jufar $\mathrm{AH}$, Zewde $\mathrm{T}$ : Prevalence of anemia among pregnant women attending antenatal care at tikur anbessa specialized hospital, Addis Ababa Ethiopia. J Hematol Thromb Dis 2014, 2. doi:10.4172/23298790.1000125

24. WHO: Hemoglobin Concentrations for the Diagnosis of Anemia and Assessment of Severity. Vitamin and Mineral Nutrition Information System Geneva: World Health Organization; 2011. http://www.who.int/vmnis/ indicators/haemoglobin.pdf, accessed [01May, 2014].

25. Cheesbrough M: District Laboratory Practice in Tropical Countries, Part I. 2nd edition. Cambridge: Cambridge University Press; 2009:196-198.

26. Alem M, Enawgaw B, Gelaw A, Kena T, Seid M, Olkeba Y: Prevalence of anemia and associated risk factors among pregnant women attending antenatal care in azezo health center Gondar town, northwest Ethiopia. J Interdiscipl Histopathol 2013, 1:137-144.

27. Karaoglu L, Pehlivan E, Egri M, Deprem C, Gunes G, Genc MF, Temel I: The prevalence of nutritional anemia in pregnancy in an east Anatolian province, Turkey. BMC Public Health 2010, 10:329.

28. Niguse O, Mossie A, Gobena T: Magnitude of anemia and associated risk factors among pregnant women attending antenatal care in shalla woreda, west arsi zone, oromia region, Ethiopia. Ethiop J Health Sci 2013 23:165-173.

29. Getachew M, Yewhalaw D, Tafess K, Getachew Y, Zeynudin A: Anemia and associated risk factors among pregnant women in gilgel gibe Dam area, southwest Ethiopia. Parasites Vectors 2012, 5:296.

30. Adama I, Khamis AH, Elbashir Ml: Prevalence and risk factors for anemia in pregnant women of eastern Sudan. Trans R Soc Trop Med Hyg 2005, 99(10):739-743.

31. Golassa L, Enweji N, Erko B, Aseffa A, Swedberg G: Detection of a substantial number of Sub microscopic plasmodium falciparum infections by polymerase chain reaction: A potential threat to malaria control and diagnosis in Ethiopia. Malar J 2013, 12:352.

32. Shulman CE, Marshall T, Dorman EK, Bulmer JN, Cutts F, Peshu N, Marsh K. Malaria in pregnancy: Adverse effects on hemoglobin levels and birth 
weight in primigravidae and multigravidae. Trop Med Int Health 2001, 6:770-778.

33. Luxemburger C, McGready R, Kham A, Morison L, Cho T,

Chongsuphajaisiddhi T, White NJ, Nosten F: Effects of malaria during pregnancy on infant mortality in an area of Low malaria transmission. Am J Epidemiol 2001, 154:459-465.

doi:10.1186/1756-0500-7-771

Cite this article as: Kefiyalew et al: Anemia among pregnant women in Southeast Ethiopia: prevalence, severity and associated risk factors. BMC Research Notes 2014 7:771.

\section{Submit your next manuscript to BioMed Central and take full advantage of:}

- Convenient online submission

- Thorough peer review

- No space constraints or color figure charges

- Immediate publication on acceptance

- Inclusion in PubMed, CAS, Scopus and Google Scholar

- Research which is freely available for redistribution 